\title{
Oligodendrocyte ARNT2 expression is altered in models of MS
}

Pierre Becquart, MSc, ${ }^{*}$ Jake Johnston, BSc,* Carles Vilariño-Güell, PhD, and Jacqueline A. Quandt, PhD

Neurol Neuroimmunol Neuroinflamm 2020;7:e745. doi:10.1212/NXI.0000000000000745
Correspondence

Dr. Quandt

jquandt@pathology.ubc.ca

\section{Abstract}

\section{Objective}

We examined expression of aryl hydrocarbon receptor nuclear translocator 2 (ARNT2), a basicloop-helix transcription factor implicated in neuronal development and axonal health, in oligodendrocyte (OL) cultures and over the course of chronic experimental autoimmune encephalomyelitis (EAE), the murine model of multiple sclerosis (MS).

\section{Methods}

We assessed OL ARNT2 expression in EAE compared with sham-immunized controls and also in OL primary cultures and over the course of dibutyryl cyclic adenosine monophosphate (dbcAMP)-mediated maturation of the immortalized Oli-neu cell line. We also tested the functional role of ARNT2 in influencing OL characteristics using small interfering RNA (siRNA).

\section{Results}

ARNT2 is localized to Olig2 ${ }^{+}$cells in healthy spinal cord gray and white matter. Despite a significant expansion of Olig ${ }^{+}$cells in the white matter at peak disease, ARNT2 is reduced by almost half in OLs, along with a reduction in the percentage of $\mathrm{ARNT}_{2}{ }^{+} / \mathrm{Olig}^{+}$cells. Mature OLs in mixed cortical cultures or OLs matured from embryonic progenitors express negligible ARNT2. Similarly, Oli-neu cells express high levels of ARNT2, which are reduced following dbcAMP maturation. siRNA-mediated knockdown of ARNT2 affected OL viability, which led to an enrichment of myelin-producing OLs.

\section{Conclusion}

The analysis of ARNT2 expression in OLs demonstrates that OL ARNT2 expression is altered in EAE and during OL maturation. Findings point to ARNT2 as an important mediator of OL viability and differentiation and warrant further characterization as a target for intervention in demyelinating disorders such as MS.

*These authors contributed equally to the manuscript.

From the Department of Pathology and Laboratory Medicine (P.B., J.J., J.A.Q.), University of British Columbia, Vancouver, BC, Canada; and Department of Medical Genetics (C.V.-G.), University of British Columbia, Vancouver, BC, Canada. 


\section{Glossary}

ARNT2 = aryl hydrocarbon receptor nuclear translocator 2; bHLH $=$ basic helix-loop-helix; cAMP $=$ cyclic adenosine monophosphate; CFA = complete Freund adjuvant; CNPase = 2', $3^{\prime}$-cyclic nucleotide $3^{\prime}$-phosphodiesterase; CNTF = ciliary neurotrophic factor; dbcAMP = dibutyryl cyclic adenosine monophosphate; EAE = experimental autoimmune encephalomyelitis; FDR = false discovery rate; GFAP = glial fibrillary acidic protein; $\mathbf{G M}=$ gray matter; HIF-1 $\boldsymbol{\alpha}=$ hypoxia inducible factor-1 alpha; IgG = immunoglobulin G; $\mathbf{L 2 F}=\log _{2}$ fold; $\mathbf{M A G}=$ myelin-associated glycoprotein; $\mathbf{M B P}=$ myelin basic protein; $\mathbf{M O G}=$ myelin oligodendrocyte glycoprotein; $\mathbf{N p a s 4}=$ neuronal PAS domain 4; $\mathrm{OL}=$ oligodendrocyte; $\mathrm{OPC}=$ OL precursor cell; PDGF = platelet-derived growth factor; siRNA = small interfering RNA; $\mathbf{W M}=$ white matter.

Multiple sclerosis (MS) is the most prevalent chronic inflammatory disease of the CNS, predominantly affecting young adults. ${ }^{1,2}$ Pathologic hallmarks of MS include inflammatory infiltrates, oligodendrocyte (OL) loss, and demyelination leading to axonal damage and lapses in action potential conduction. ${ }^{3,4}$ Axonal neurodegeneration is observed very early in the disease course and is believed to be the primary cause of debilitating physical symptoms including sensory alterations, loss of balance, disturbances of vision or speech, extreme fatigue, muscle weakness, and paralysis, in addition to mental health issues including depression and cognitive impairment. ${ }^{1,5-7}$ The disease course of MS is typically relapsing-remitting, characterized by alternating clinical attacks and periods of stability with complete or partial recovery, which typically transitions into secondary progressive MS as deterioration progresses. ${ }^{8}$ Neuroprotection in MS is the strategic prevention of irreversible damage to neuronal and glial cell populations and the promotion of neural regeneration. ${ }^{9}$ Most existing MS therapies are immunomodulatory in nature and add support to the hypothesis that inflammation drives the neurodegeneration observed. ${ }^{8,10}$ Immune-mediated damage is amplified by neurodegeneration in damaged axons including anterograde or retrograde axonal or transsynaptic degeneration, synaptic pruning, and neuronal or OL death. ${ }^{11}$

OL development begins when neural progenitor cells in the ventricular zone are exposed to environmental signals including platelet-derived growth factor (PDGF), fibroblast growth factor-2, insulin-like growth factor-I, and epidermal growth factor to differentiate into highly proliferative, migratory, and bipolar OL precursor cells (OPCs). ${ }^{12-14}$ These growth factors also promote the widespread migration and proliferation of OPCs throughout the entirety of the CNS. ${ }^{13,15}$ OPC molecular markers include neural/glial antigen 2 and PDGF receptor $\alpha$ and the expression of transcription factors Olig1 and Olig2. ${ }^{16}$ Contrary to the factors that support OPC proliferation, thyroid hormone triiodothyronine (T3), neuregulin-1 and transforming growth factor- $\beta 1$, ciliary neurotrophic factor (CNTF), and cyclic adenosine monophosphate (cAMP) promote OPC maturation. ${ }^{17-21}$ Hallmarks of OL maturation and myelination include expression of $\mathrm{OL}$ surface proteins $\mathrm{O} 1$ and $\mathrm{O} 4$, $2^{\prime}, 3^{\prime}$-cyclic nucleotide $3^{\prime}$-phosphodiesterase (CNPase), myelin basic protein (MBP), proteolipid protein, myelin oligodendrocyte glycoprotein (MOG), and myelinassociated glycoprotein (MAG) and expression of transcription factors Olig1 and Olig $2^{16,22}$; transcription factors that influence gene expression (by driving or repressing transcription) may also be relevant to these processes. It is apparent that there are many complex timing and molecular factors in OL maturation, ultimately leading to myelination of neurons. Understanding and capitalizing on these maturation mechanisms has tremendous potential for neuroprotective and neuroregenerative MS therapies, as improving myelination processes in OLs could decrease axonal loss and ultimately translate to an improved prognosis for patients with MS.

Aryl hydrocarbon receptor nuclear translocator 2 (ARNT2) is a member of the basic helix-loop-helix (bHLH) PAS transcription factor family, which forms heterodimers to regulate target gene expression and is highly responsive to environmental and physiologic signals. ${ }^{23}$ It is highly expressed in the CNS and plays an important role in neuronal development. ARNT2 has been linked to neuroprotection: Arnt2 gene transcript levels declined significantly following 2 hours of postischemic reperfusion, preceding neuronal death at 24 hours. ${ }^{24}$ ARNT2 was thought to protect against apoptosis, with small interfering RNA (siRNA)mediated downregulation of ARNT2 driving apoptosis of PC- 12 cells, and rapid and strong downregulation of ARNT2 before oxidative stress-induced death. ${ }^{24} \mathrm{~A}$ lack of hypothalamic neuroendocrine lineage formation, impaired regulation of hypoxia inducible factor- 1 target genes, and thymic defects contribute to perinatal death of Arnt 2 homozygous knockout mice and rats within the first day to 2 weeks after birth. $^{25-28}$

Previous work from our group has shown that neuronal ARNT2 expression is upregulated in response to certain stressors, whereas declining ARNT2 expression is associated with a decrease in cellular health/viability. ${ }^{29,30}$ ARNT2 expression decreased at peak disease in the brains and spinal cords of mice immunized for experimental autoimmune encephalomyelitis (EAE), the prototypical model of MS. In those studies, we observed ARNT2 expression in astrocytes. ${ }^{29}$ This study examines ARNT2 expression in OLs during EAE and characterizes its expression through differentiation in vitro and its functional relevance to OL maturation. 


\section{Methods}

\section{EAE induction}

Female C57BL/6 mice (Jackson Laboratories, 6-8 weeks of age) were immunized for chronic progressive EAE as described $^{31}$ with $200 \mu \mathrm{g}$ of $\mathrm{MOG}_{35-55}$ peptide (MEVGWYRSPFSRVVHLYRNGK; Stanford Pan Facility, Stanford, $\mathrm{CA}$ ) in incomplete Freund adjuvant boosted with $4 \mathrm{mg} / \mathrm{mL}$ Mycobacterium tuberculosis (H37Ra, now complete Freund adjuvant $[\mathrm{CFA}]$ ), whereas control or sham-immunized mice were immunized with CFA only. All mice received pertussis toxin (List Biologicals, Campbell, CA) intraperitoneally that day and 2 days later. Mice were weighed biweekly and scored daily on a scale from 0 to 5 for severity of clinical symptoms: 0-0.5 indicated no disease/distal limp tail, 1.0 limp tail, 2.0 weakness in one or 2.5 in both hind limbs/slipping on bars, 3.0-3.5 paralysis in one or both hind limbs, 4.0-4.5 hind limb paralysis plus weakness in one or in both forelimbs, and 5 for moribund animals. Sections spanning different levels of the spinal cord (T1/2, T5/6, T12/13, and L5/6) were examined in 6 CFA sham-immunized mice and 5 EAE mice at peak disease (day 18) to total 22-28 sections per treatment group. All sections of the EAE spinal cords showed evidence of immune infiltration in mice whose disease severity scores averaged $3.25 \pm 0.67$ and ranged from 2.5 to 4.0. Animal use was approved by the University of British Columbia Animal Care Committee (certificate \#A130281) and per CCAC guidelines.

\section{Processing of EAE tissues for immunohistochemistry}

Mice were transcardially perfused with PBS, followed by $10 \%$ buffered formalin, while under anesthesia with a ketamine/ xylazine cocktail. ${ }^{29}$ After 3-5 days postfixation, spinal cords were removed and cryoprotected in 30\% sucrose solution. After trimming into 5-mm sections and embedding in optimal cutting temperature compound (VWR, Radnor, PA), 5- $\mu \mathrm{m}$ sections were prepared on a cryostat. Sections were permeabilized with $0.1 \%$ triton X-100 (Fisher) and blocked before incubation with antibodies to ARNT2, glial fibrillary acidic protein (GFAP), Olig2, and immunoglobulin (IgG) control antibodies overnight (see supplementary table e-1, links.lww.com/NXI/A253). After incubation with secondary antibody and nuclear staining with DAPI, Zeiss software Zen (Version 2.0.0.0) was used for image analysis. Nuclei positive for Olig2 (2 SDs greater than the mean intensity measured in central canal ependymal (Olig2 negative) cells and negative for GFAP (SD of GFAP mean intensity less than 700) were selected: the average fluorescence intensity per pixel for ARNT2 over the area of the positive nucleus was measured. ARNT2 intensities were first normalized to the average value for ARNT2 mean intensity in 10 random nucleus-free regions of the gray matter on each section to account for any background staining between sections. Cells were considered ARNT2 positive when ARNT2 mean intensity over the area of the nucleus was 2 SDs above the average background intensity from 10 gray matter areas. The number of OLs in the gray (GM) or white matter (WM) was assessed and normalized to the surface area of the WM or GM mask to obtain cell number per $\mathrm{mm}^{2}{ }^{30}$

\section{Primary cortical neuronal-enriched or OPC cultures}

Embryonic day 18 (E18) rat cortices were provided by Dr. Shernaz Bamji (University of British Columbia, Vancouver, BC) and cultured as previously described ${ }^{32}$ in Neurobasal ${ }^{\circledR}$ media (Thermo Fisher Scientific, Waltham) supplemented with B-27 (Gibco, Thermo Fisher Scientific). Primary mouse oligospheres and OPCs were generated from mouse neurospheres as described ${ }^{33}$ and maintained in proliferation medium (DMEM/F12, $25 \mu \mathrm{g} / \mathrm{mL}$ insulin, $100 \mu \mathrm{g} / \mathrm{mL}$ apotransferrin, $20 \mathrm{~nm}$ progesterone, $60 \mu \mathrm{m}$ putrescine, and $30 \mathrm{~nm}$ sodium selenite, $20 \mathrm{ng} / \mathrm{mL}$ PDGF-AA, $20 \mathrm{ng} / \mathrm{mL}$ bFGF) as oligospheres in suspension or as adherent OPCs. For differentiation experiments, OPCs were maintained in OPC proliferation medium for 5 days and then cultured in differentiation medium (neural culture medium containing 10 $\mathrm{ng} / \mathrm{mL}$ CNTF [Peprotech], $5 \mu \mathrm{g} / \mathrm{mL} \mathrm{N}$-acetyl-L-cysteine, and $50 \mathrm{nM}$ triiodothyronine) for 5 days.

\section{Immortalized OPC cultures and siRNA- mediated knockdown of ARNT2}

A useful in vitro model of OPC maturation is the immortalized O-2A OPC cell line Oli-neu, ${ }^{34}$ which can be matured into myelinating OLs using dibutyryl cAMP (dbcAMP) or neuronal culture media. ${ }^{35}$ Oli-neu cells (neuimmortalized OPC cells, provided by C. Pallen in collaboration with R. Kothary, University of Ottawa, Canada) were maintained in growth medium: DMEM medium containing SATO supplement (1\% horse serum, Invitrogen; $10 \mu \mathrm{g} / \mathrm{mL}$ holo-transferrin, Sigma; $10 \mu \mathrm{g} / \mathrm{mL}$ insulin, Sigma; $0.1 \mathrm{mM}$ putrescine, Sigma; $0.2 \mu \mathrm{M}$ progesterone, Sigma; $0.5 \mu \mathrm{M}$ T3 hormone, Sigma; $0.22 \mu \mathrm{M}$ sodium selenite, Sigma; $0.52 \mu \mathrm{M}$ Lthyroxine, Sigma) at $5 \% \mathrm{CO}_{2}$ and $37^{\circ} \mathrm{C}$. At day 3 , cells received differentiation medium: DMEM containing SATO supplement and $1 \mathrm{mM}$ dbcAMP (Sigma). For siRNA knockdown, Oli-neu cells were plated in a 96-well plate as above, and on day 3 , cells received a media change or received the differentiation medium (DMEM, SATO supplement and $1 \mathrm{mM}$ dbcAMP). At day 6 , cells were transfected with a scramble siRNA 5'rCrUrArArCrGrCrGrArCrUrArUrArCrGrCrGrCrArArUrArUrGrGrU3' 5'rCrArUrArUrUrGrCrGrCrGrUrArUrArGrUrCrGrCrGrUrUAG3' or a siRNA targeting ARNT2 5'rCrUrGrArUrGrArGrArUrCrGrArGrUrArCrGrUrCrArUrCTG3' 5'rCrArGrArUrGrArCrGrUrArCrUrCrGrArUrCrUrCrArUrCrArGrArG3'

(3 pmol per well) using the Lipofectamine transfection reagent RNAiMAX ( $0.1 \mu \mathrm{L}$ per well) (Invitrogen) and analyzed 48-72 hours later with immunocytochemistry.

\section{Immunocytochemistry}

After fixation, cells were permeabilized with $0.1 \%$ Triton $\mathrm{X}-100$ (Fisher) and blocked with normal serum before incubation with primary antibodies or IgG controls (supplementary table 1, links.lww.com/NXI/A253) overnight and 
then washed with PBS and incubated with secondary antibodies for 1 hour at room temperature. After washing with PBS and staining nuclei with Hoechst or DAPI, cells were visualized as for immunohistochemistry. Twenty images were taken of different regions in each well, with at least 3 technical replicates. ARNT2 expression in cells was assessed by quantifying the mean intensity of ARNT2 over the area of the nucleus and then compared between all nuclei or nuclei surrounded by MAG.

\section{RNA-seq}

Cells treated for siRNA-mediated knockdown were harvested after 48 hours of knockdown with a scramble or ARNT2specific siRNA. After washing, cells were lysed and processed with RNAzol and confirmed for ARNT2 knockdown of $70 \%-80 \%$ in each paired sample set. Sample quality control was performed using the Agilent 2100 Bioanalyzer. Qualifying samples were then prepared following the standard protocol for the NEBNext Ultra II Stranded mRNA (New England Biolabs). Sequencing was performed on the Illumina NextSeq 500 with paired end $42 \times 42 b p$ reads. Sequencing data were demultiplexed using Illumina's bcl2fastq 2 and aligned to the Mus musculus (mm10) reference genome using the STAR aligner. $^{36}$ Assembly and gene counts were generated using Cufflinks $^{37}$ through bioinformatics apps available on Illumina Sequence Hub. Differential expression between scramble and ARNT2-targeted knockdown was determined with DESeq2 lfcShrink on genes with a minimum of 10 reads across samples. Enrichment analysis of Gene Ontologies and Kyoto Encyclopedia of Genes and Genomes pathways was calculated using the Database for Annotation, Visualization, and Integrated Discovery v6.8. ${ }^{38}$ Benjamini-Hochberg false discovery rate (FDR) correction for multiple testing was used for gene expression profiling and pathway analysis.

\section{Statistical analysis}

All statistical analysis and graphing were performed using GraphPad Prism (version 8, La Jolla, CA). For analysis of ARNT2 intensities in Oli-neu and analysis of different sections of the spinal cord or different siRNA knockdown approaches, 2-way analysis of variance were performed, followed by the Sidak multiple comparisons test. For analysis of ARNT2 intensity in cortical neuronal-enriched primary cultures and ARNT2 mean intensity analysis in WM and GM, the Mann-Whitney $t$ test was performed.

\section{Data availability}

Data not provided in the article because of space limitations can be shared at the request of other investigators for purposes of replicating procedures and results.

\section{Results}

\section{OL number and ARNT2 expression change during EAE disease course}

A transcriptome database shows that ARNT2 expression is decreased sequentially when comparing OPCs with newly formed OLs and then with myelinating OLs in mouse cortical populations (figure 1). We next characterized the expression of ARNT2 in OLs of EAE and sham-immunized mice. At peak disease, thoracic and lumbar spinal cord sections from EAE mice showed a significant increase in the number of Olig2 ${ }^{+}$cells (GFAP ${ }^{-}$OLs and OPCs) within spinal WM regions compared with sham-immunized mice (figure 2A). The mean OL/OPC count in the thoracic $\left(258.3 \pm 142.4\right.$ cells $\left./ \mathrm{mm}^{2}, \mathrm{n}=12\right)$ and lumbar $(383.8 \pm$ 212.3 cells $\left./ \mathrm{mm}^{2}, \mathrm{n}=10\right)$ regions of WM of EAE mice increased compared with WM of sham mice in the thoracic $\left(140.2 \pm 32.2\right.$ cells $\left./ \mathrm{mm}^{2}, \mathrm{n}=14\right)$ and lumbar $(175.1 .0 \pm 40.4$ cells $\left./ \mathrm{mm}^{2}, \mathrm{n}=13\right)$ regions, respectively $(p=0.0352$ and $p=$ 0.0003 ). No significant differences in OPC/OL count were observed in the cervical WM or any GM spinal regions (figure 2A).

Olig2 ${ }^{+}$cells expressing ARNT2 could be detected throughout the WM and GM of sham-immunized mice (figure 2B-C). Although $90 \%-100 \%$ of Olig2 ${ }^{+}$cells in the WM and GM at each level of sham-immunized animals are positive for ARNT2, the percentage of Olig2 ${ }^{+}$cells positive for ARNT2 was significantly lower at the thoracic and lumbar spinal cord levels of EAE animals; this was evident in both WM regions (thoracic: sham \%88.4 $\pm 5.7, \mathrm{n}=14$ vs EAE \%51.7 $\pm 18.7, \mathrm{n}=12$; $p<0.0001$; lumbar: sham $\% 92.3 \pm$ $5.6, \mathrm{n}=13$ vs $\mathrm{EAE} \% 61.3 \pm 16.3, \mathrm{n}=8 ; p<0.0001)$ and $\mathrm{GM}$ regions (thoracic: sham $\% 93.0 \pm 4.1, \mathrm{n}=14$ vs EAE $\% 56.0 \pm$ $21.4, \mathrm{n}=13 ; p<0.0001$; lumbar: sham $\% 94.9 \pm 3.6, \mathrm{n}=13$ vs EAE \%50.6 $\pm 20.1, \mathrm{n}=8 ; p<0.0001)$. Similarly, ARNT2 intensities of OLs/OPCs (Olig2 $2^{+} / \mathrm{GFAP}^{-}$cells) were significantly lower in EAE animals than sham-immunized animals in both WM $(1.56 \pm 0.47$ vs $2.67 \pm 0.43, p<0.0001)$ and GM regions $(1.54 \pm 0.66$ vs $3.56 \pm 0.58 ; p<0.0001)$ (figure 2D) examined.

\section{Primary OL cultures display low ARNT2 expression}

We next examined ARNT2 expression in OLs within mature neuronal-enriched cortical cultures. Our DIV14 cultures showed few contaminating CNPase ${ }^{+}$mature OLs, yet those detected were consistently low or negligible for ARNT2 expression (figure $3 \mathrm{~A}-\mathrm{C}$ ), particularly compared with the average and range in intensities of the mixed population of neurons, astrocytes, and few contaminating microglia, which were also present: OLs $1,850 \pm 30.1$ vs other cell types 4,455 \pm $60.1(p<0.0001)$. We also examined ARNT2 expression in primary enriched cultures of murine OPCs (figure 3D-E) and compared expression in these OPCs with OLs that had been matured with growth factors (figure 3F-I). Although ARNT2 was readily apparent in primary OPCs (figure $3 \mathrm{D}-\mathrm{E}$ ), it was not detected in $\mathrm{MBP}^{+}$cells despite being very prominent in $\mathrm{GFAP}^{+}$astrocytes. Both OL cultures exhibited low or negligible ARNT2 expression compared with that observed in OPCs or surrounding neuronal or astrocytic populations (figure 3F-I). 


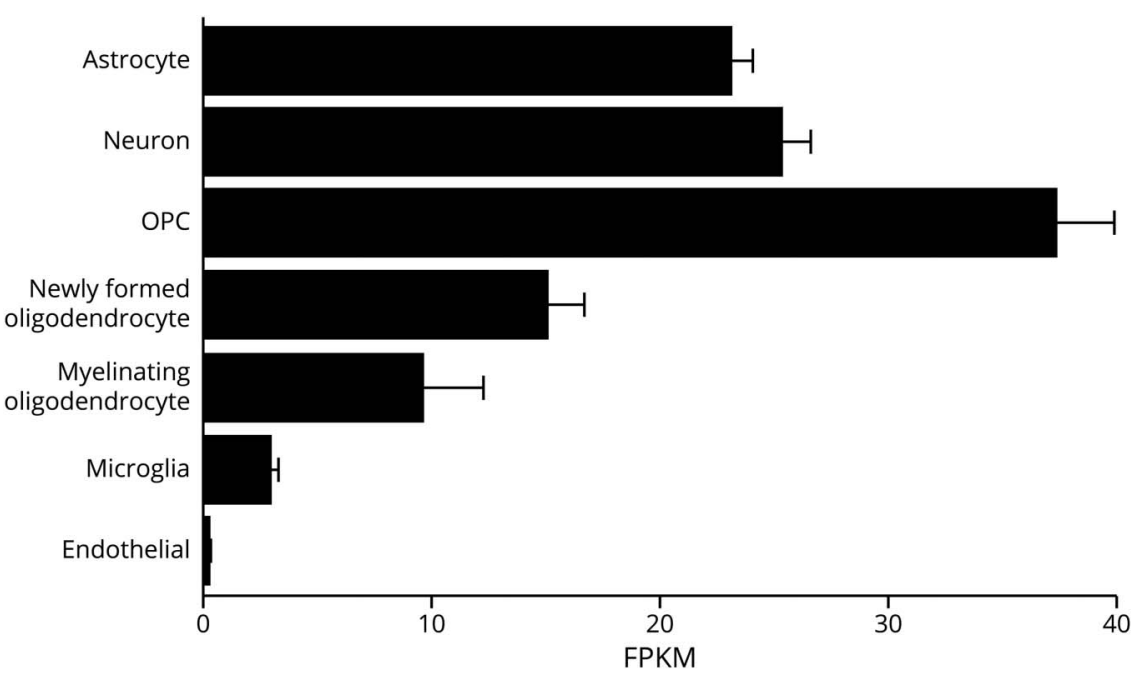

ARNT2 mRNA was detected in neurons and glia. Transcription of ARNT2 mRNA is highest in OL precursor cells and progressively decreased as they developed into newly formed OLs and then matured into myelinating OLs. ${ }^{60}$ ARNT2 = aryl hydrocarbon receptor nuclear translocator 2; FPKM = Fragments per kilobase of transcript per million mapped reads; OL = oligodendrocyte.

\section{Neutralizing ARNT2 expression limits the expansion of immature cells and enriches for mature Oli-neu cells}

The Oli-neu cell line was used to examine the functional relevance of ARNT2 expression to the process of OL maturation. Immortalized Oli-neu cells are OPCs, which can undergo differentiation in vitro to produce myelin components integrated within complex cytoplasmic processes including MAG ${ }^{34,35}$ and CNPase. ${ }^{39,40}$ Immature Oli-neu cells were compared with mature cells following 5 days of treatment with dbcAMP where mature cells are distinguished by MAG positivity on complex arbors extending from the cell body. Immature Oli-neu cells express moderate to high levels of ARNT2, which drop significantly by 5 days of maturation with dbcAMP (figure 4A). Maturation with dbcAMP reduced ARNT2 mean intensity in the presence of scramble siRNA (scr) from $1.26 \pm 0.12$ (scr-dbcAMP) to $1.19 \pm 0.045$ $(\mathrm{scr}+\mathrm{dbcAMP})(p<0.0001)$ (figure $4 \mathrm{C})$. ARNT2-targeting siRNA reduced the intensity of ARNT2 expression in immature and mature cultures significantly (-dbcAMP scr 1.26 \pm 0.12 vs ARNT2 $0.99 \pm 0.06, p<0.0001 ;+$ dbcAMP scr 1.19 \pm 0.045 vs ARNT2 $1.02 \pm 0.06, p<0.0001$ ) (figure 4C). We further found that siRNA-mediated knockdown of ARNT2 affected the density of immature and mature Oli-neu significantly, lowering density, and likely proliferation over the knockdown period from $185.4 \pm 63.9$ to $62.3 \pm 43.6$ cells/ $\mathrm{mm}^{2}(p<0.0001)$ for the immature culture and from $160.1 \pm$ 99.1 to $554.3 \pm 47.5$ cells $/ \mathrm{mm}^{2}$ for the mature culture $(p<$ 0.0001 ), a drop of $33 \%$ and $34 \%$, respectively (figure 4B). SiRNA-mediated knockdown of ARNT2 had no significant effect on the proportion of mature MAG-expressing Oli-neu cells maintained in proliferation media (lipofectamine reagent alone-LP $0.2 \pm 0.7 \%$ vs scr $0.2 \pm 1.2 \%$ vs ARNT2 0.7 $\pm 3.7 \%$ ) (figure 4D) suggesting that ARNT2 knockdown alone is not sufficient to drive full Oli-neu maturation/MAG expression. In contrast, the percentage of mature OLs was nearly doubled with ARNT2 knockdown 5 days after the start of maturation with dbcAMP to $20.6 \pm 12.4 \%$ mature cells in the culture compared with $13.6 \pm 9.5 \%$ with maturation in the presence of LP alone or $12.2 \pm 8.2 \%$ in the presence of LP plus scramble siRNA $(p<0.0001)$. In this regard, elimination of ARNT2 significantly enriched the percentage of $\mathrm{MAG}^{+}$mature cells in cultures that received dbcAMP.

\section{Targeting ARNT2 alters myelin and differentiation pathways}

Transcriptome analyses of Oli-neu cells treated with siRNA-targeted ARNT2 knockdown $(n=3)$ showed significant differences in expression for 12 genes $(F D R<0.05$, $\log _{2}$ fold $\left.(\mathrm{L} 2 \mathrm{~F})>|0.5|\right)$ compared with scramble-treated cells $(n=3)$ (figure $5 A)$. In addition to changes in gene expression, we noted a change in morphology with an elongated shape and increased numbers of processes (figure $5 B$ ) that mirror changes observed in OPC differentiated ex vivo in previous studies. ${ }^{41}$ Pathway analysis of 195 genes with a $p$ value of $<0.05$ before correction and $\mathrm{L} 2 \mathrm{~F}>|0.5|$ identified enrichment in pathways related to axon guidance, cell adhesion, CNS myelination as well as extracellular matrix-receptor interactions, and PI3K-Akt signaling pathways (figure 5C).

\section{Discussion}

Given the importance of myelin to neuronal saltatory conduction and axonal support, ${ }^{42}$ strategies that support OPC maturation into myelinating OLs also have promise as neuroprotective therapies. ${ }^{43}$ The transcription factor ARNT2 is highly expressed in neurons and has a critical 


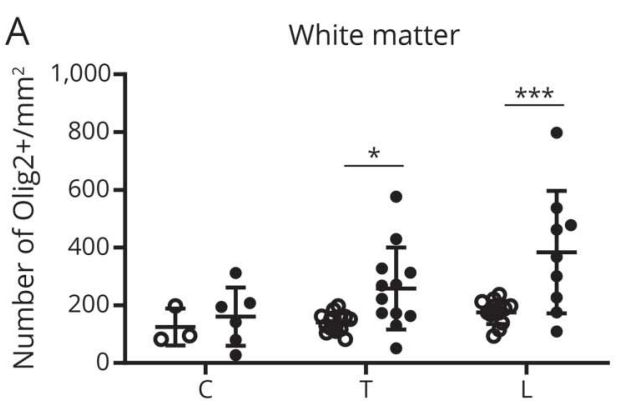

Level of spinal cord

B

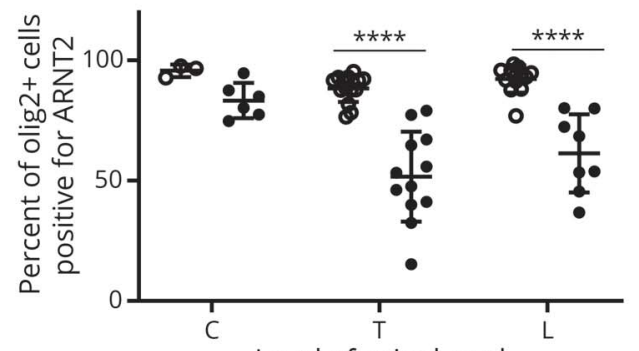

Level of spinal cord
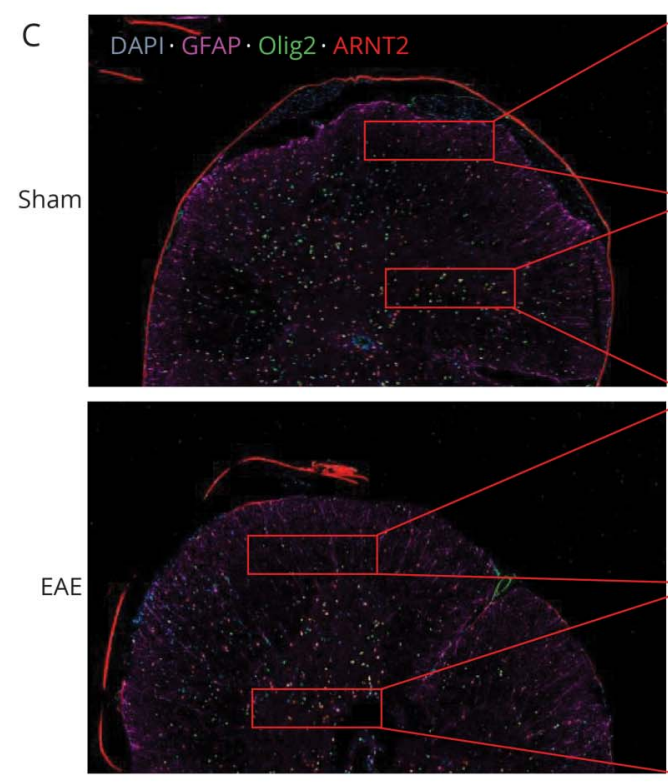

D

White matter

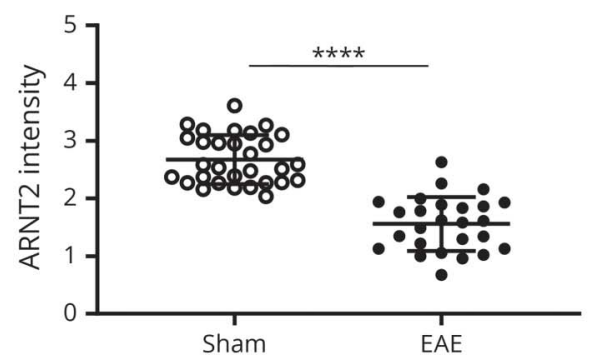

Gray matter

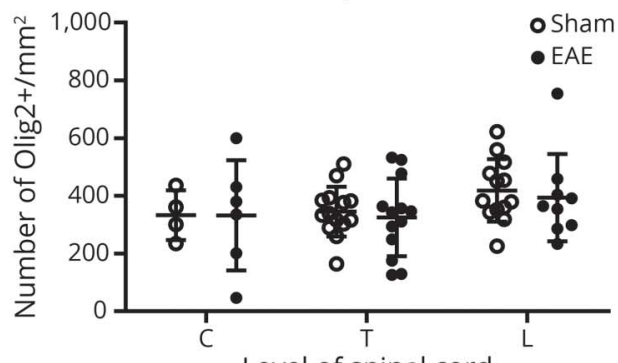

Level of spinal cord

Gray matter

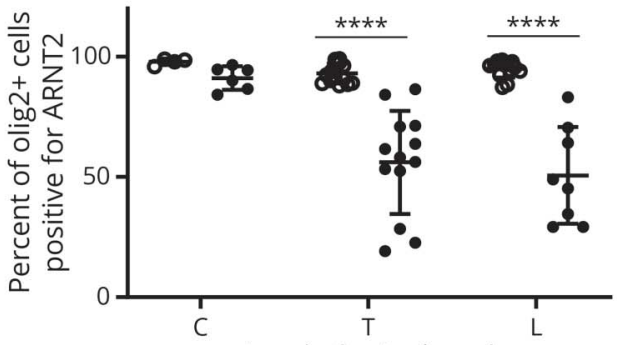

Level of spinal cord
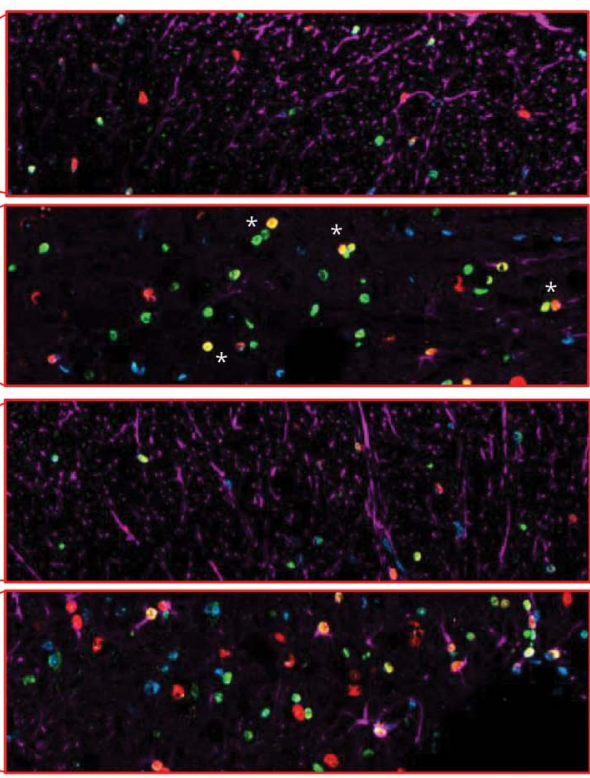

E

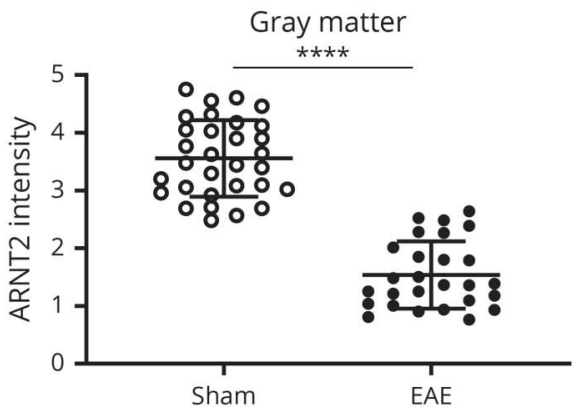

(A) The number of Olig2 $2^{+} /$glial fibrillary acidic protein cells (OLs) was significantly increased in the WM regions of EAE mice compared with sham-immunized mice. " $C$ " denotes the cervical, " $\mathrm{T}$ " the thoracic, and " $\mathrm{L}$ " the lumbar spinal section. No significant differences were observed in the cervical or GM spinal regions. (B) The percentage of Olig2 ${ }^{+}$cells positive for ARNT2 is reduced in the thoracic and lumbar regions in both WM and GM of EAE mice. (C) IHC of mouse spinal cord sections from sham-immunized (upper) and EAE (lower) mice shows a visible decrease in ARNT2-expressing Olig2 ${ }^{+}$OLs (yellow). (D and E) ARNT2 intensity decreased in WM and GM in pooled thoracic and lumbar spinal regions in mice at peak EAE disease relative to sham-immunized

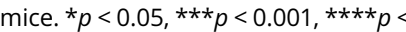
0.0001 , mean $\pm S D$ is shown. (A-B) Two-way ANOVA, followed by the Sidak multiple comparisons test. (D and E) Mann-Whitney $t$ test. ANOVA = analysis of variance; ARNT2 = aryl hydrocarbon receptor nuclear translocator 2; $E A E=$ experimental autoimmune encephalomyelitis; $\mathrm{GM}=$ gray matter; $\mathrm{OL}=$ oligodendrocyte; WM = white matter. function in neuronal development. ${ }^{44}$ Here, we demonstrate that ARNT2 is expressed in OPCs and OLs from 3 sources: mouse spinal cords, primary rodent cells, and immortalized
Oli-neu cells. This description of ARNT2 expression in OLs or their precursors provides insight into a potential differentiation pathway for myelin production that may be 

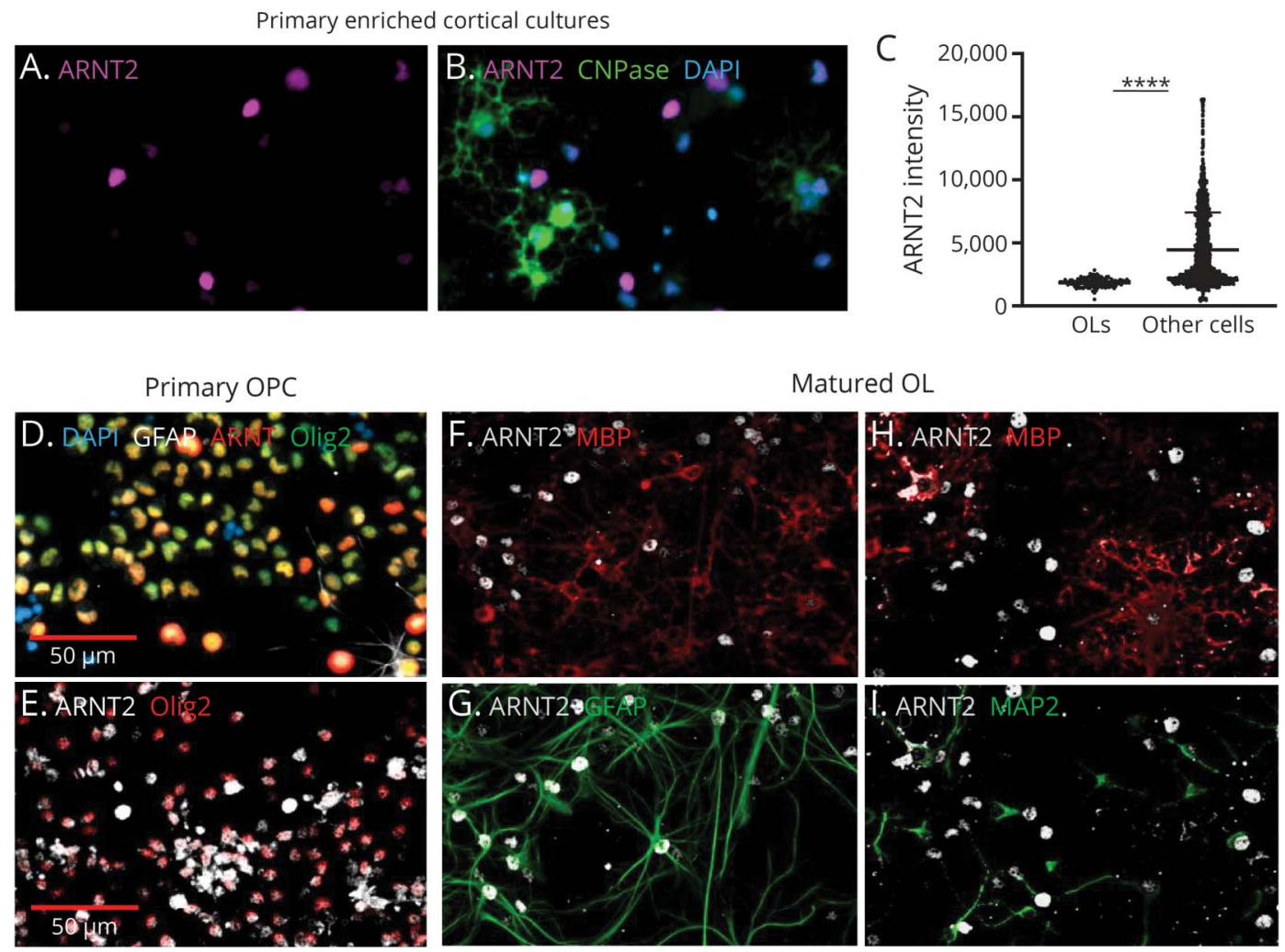

(A-C) Mature OLs identified as CNPase+ cells in DIV14 neuronal-enriched primary cortical cultures exhibited lower ARNT2 expression relative to surrounding CNPase- cells that were typically neurons or astrocytes. ( $D$ and E) Primary murine OL precursor cells enriched from neuronal progenitor populations were typically high expressors of ARNT2 as shown by frequent coexpression of Olig2 and ARNT2. Following maturation with growth factors (F-l), increases in MBP ${ }^{+}$ cells with numerous complex cell processes were observed; these cells were typically negligible for ARNT2 compared with GFAP ${ }^{+}$astrocyte (G) and rare MAP2 ${ }^{+}$

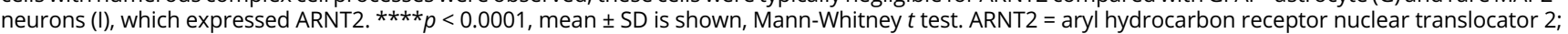
CNPase = 2', 3'-cyclic nucleotide 3'-phosphodiesterase; GFAP = glial fibrillary acidic protein; MBP = myelin basic protein; OL = oligodendrocyte.

influenced by ARNT2. Mature Oli-neu cells showed decreased ARNT2 expression compared with immature Olineu cells. Consistent with these findings, low ARNT2 expression was also observed in primary culture mature OLs compared with surrounding cells in neuronal-enriched rat cortical culture. Our findings demonstrate differential ARNT2 expression between mature and immature OL cells, although further studies are necessary to determine whether ARNT2 regulation plays a direct functional role in OL maturation and myelination processes. ARNT2 knockdown in Oli-neu cultures showed increases in Cntn1, Olig1, and Smocl by 2 days after treatment, each of which shows factors which in vivo have the highest relative expression in cortical OPCs and decline successively in newly myelinating OLs and mature OLs. ${ }^{45}$ These early increases in Cntnl and Smoc1 after ARNT2 knockdown mirror those in a functional genomic analysis of OL differentiation performed ex vivo on rat OPCs where early increases in Smoc1 and Cntn1 were detected over the first 2-3 days. ${ }^{41}$ This suggests that decreases in ARNT2 expression in vivo may be coinciding with an OPC mobilization and early stages of differentiation necessary for myelination in later stages.

Differences in OL ARNT2 protein expression were revealed between the GM and WM of sham and EAE mice, suggesting that pathologic processes in EAE may be the driver of altered ARNT2 expression in OLs. Our own work in EAE showed that the degree of inflammatory infiltration, demyelination, and axonal damage all correlated with reduced levels of ARNT2 in neurons, ${ }^{30}$ and the same correlations may exist here. The thoracic and lumbar spinal sections of EAE mice exhibited reduced GM and WM OL ARNT2 expression and an increased number of WM OL cells. However, these changes were not detected in cervical regions of the cord, likely because pathology (axonal loss, demyelination, and inflammation) is greater in the lower regions of the cord in this model of ascending paralysis. ${ }^{46}$ Our in vitro studies revealed that maturation of primary cultures and immortalized OPC cultures gave way to reduced ARNT2 expression, which matched the RNAseq data that showed sequentially lower levels of RNA message in mouse cortical samples comparing OPCs to immature OLs to myelinating OLs (per figure 1). Although our data showed enrichment of myelinating cells in the presence of maturation signals and ARNT2 knockdown, ARNT2 knockdown alone did not enhance maturation as measured by MAG expression at the time we examined shortly after knockdown. This is likely because MAG and 


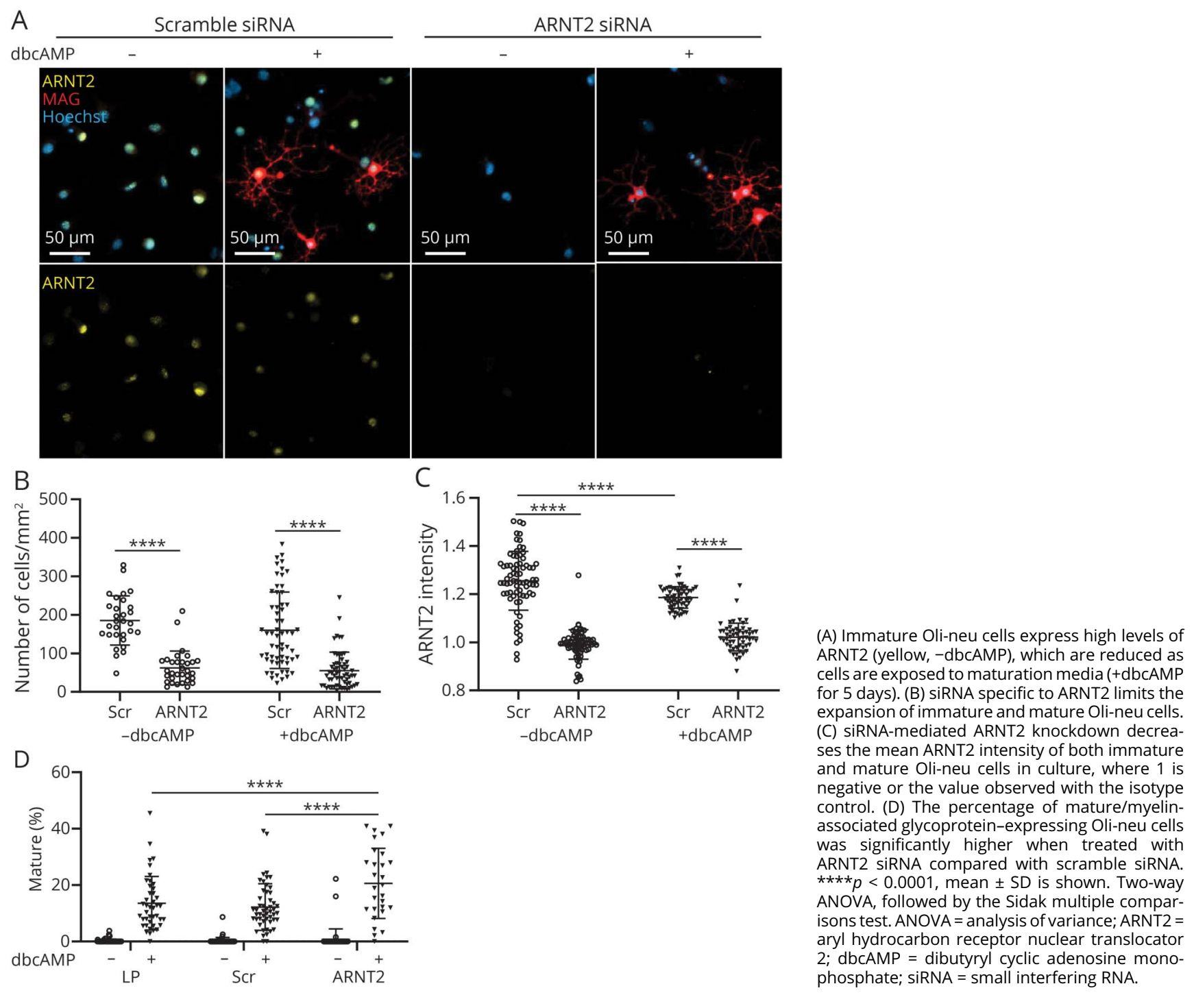

other myelin proteins are expressed at a later stage in the differentiation process. ${ }^{41}$ Oli-neu could not be followed for longer than 3 days due to reduced viability after $\geq 75 \%$ decrease in ARNT2 expression. Because ARNT2 knockdown tended to limit the expansion of ARNT2+ Oli-neu (and because immature Oli-neu also had higher levels of ARNT2 at the outset), our results may also be explained by the association of ARNT2 with cell proliferation and cell cycling pathways. $^{24}$ Indeed, the combination of reduced proliferation and early signals to differentiate may be what enables enrichment of mature OLs in our cultures and in turn may drive maturation in vivo.

Given that ARNT2 has been proposed as an inhibitor of apoptosis, it may be that the loss of ARNT2 puts OLs at risk of increased apoptosis and ultimately loss in response to inflammatory mediators or other stressors in the EAE lesion. Furthermore, mutations in ARNT2 that were thought to influence neuronal development may instead contribute to failures to generate mature OLs or to mobilize OPCs at times of need and failures to myelinate, as observed in affected members of a family with ARNT2 frameshift mutations: children had normal brain volume at birth, but all subsequently developed secondary microcephaly within months. This progressive neurodegenerative condition may be attributed to decreased dendritic connection or activity of a (near) normal number of neurons, ${ }^{47}$ but could rather be linked to greater demonstrated degrees of hypomyelination or immature myelin by MRI. $^{48}$

Finally, recent studies have shown that unlike the typical homo- or heterodimerization patterns observed in bHLH family members where dimerization drives transcription of a set of downstream target genes, ARNT2 may act as a repressor that when bound to any of its partners acts as 
Figure 5 ARNT2 knockdown alters myelin and differentiation pathways
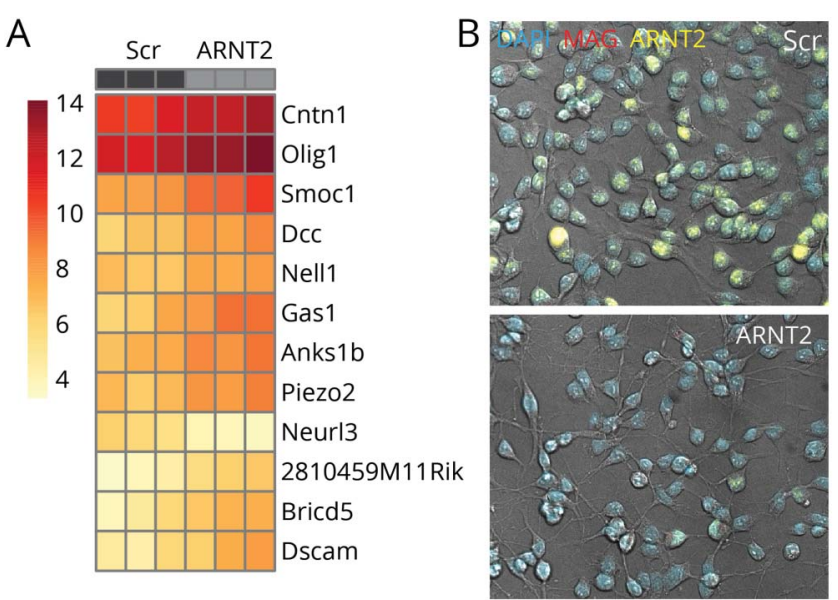

C

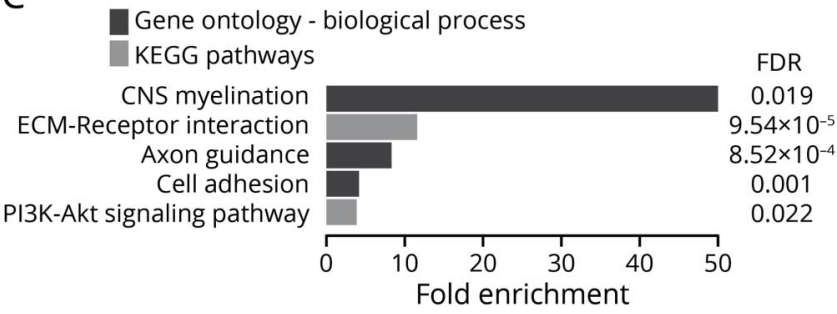

(A) Heatmap of normalized transform gene expression $\left(\log _{2}(n+1)\right)$ in Olineu cells after treatment with scramble or ARNT2-targeted small interfering RNA $(L 2 F>|0.5|, F D R<0.05)$. (B) Oli-neu cells show elongated cell bodies and greater spreading with greater processes associated with decreased ARNT2 expression (yellow) following ARNT2 knockdown (KD). (C) Pathway analysis of 195 genes with a $p$ value of $<0.05$ and $\mathrm{L} 2 \mathrm{~F}>|0.5|$ secondary to ARNT2 KD in Oli-neu cells. ARNT2 = aryl hydrocarbon receptor nuclear translocator 2; ECM = extracellular matrix; FDR = false discovery rate; KEGG = Kyoto Encyclopedia of Genes and Genomes; $\mathrm{L} 2 \mathrm{~F}=\log _{2}$ fold; Scr = scramble.

a block to transcription rather than a driver. ARNT2 is the major heterodimeric partner of neuronal PAS domain 4 (NPAS4) in the brain ${ }^{49,50}$; NPAS4/ARNT2 complexes regulate brain-derived neurotrophic factor transcription, a major mediator of physiologic functions including activity-dependent functions, axonal growth, and a key molecule in neuronal and axonal survival with impact on memory, learning, and neurogenesis. ${ }^{51-55}$ Recently, a repressor role in this pairing was described in neurons, ${ }^{56}$ and given that other potential partners of ARNT2 may be expressed by OLs at different stages of differentiation, identifying additional partners and downstream targets are a key priority in characterizing functional roles for ARNT2 in OL development. Because ARNT2 deletion limited expansion but did not drive maturation to the extent that myelin proteins were significantly increased, we proposed that it may be serving to fine tune gene expression in OLs as well, perhaps to limit timing when maturation or differentiation might otherwise occur. This may explain why ARNT2 expression is reduced in EAE, as a means to allow and more precisely orchestrate myelination and thus repair. Notably, Cntn 1 and other contactin family members are involved in OL membrane extension and myelination, including the signaling between axons and myelinating glial cells for radial and longitudinal organization of myelinated axons. ${ }^{57}$ Of interest, ARNT2 does exhibit the ability to interact with hypoxia inducible factor-1 alpha (HIF-1 $\alpha$ ) and induce hypoxia element-driven gene expression ${ }^{58}$; this observation links the high metabolic demands of OLs to environmental regulation of myelinating processes described previously through HIF-1a. ${ }^{59}$

To discern these possibilities, targeted knockdown of ARNT2 to OLs at key time points in the onset and progression of disease in vivo will be required. Similarly, targeting ARNT2 in either immature or mature OL populations will help discern ARNT2's potential for therapeutic intervention as a means to influence remyelinating and reparative processes that ultimately may benefit those affected by demyelinating disorders such as MS.

In summary, this study characterizes ARNT2 protein expression in OLs in vivo and in vitro. We propose that reduction of OL ARNT2 expression is an important mechanism to orchestrate OPC maturation and remyelination based on higher ARNT2 expression in immature OLs that decreases as cells mature. Although further studies are needed to understand the specific inflammatory cells or mediators that regulate OPC and OL ARNT2 expression during chronic inflammatory settings, the potential for ARNT2 and its partners to influence reparative processes warrants its consideration as a target for intervention in demyelinating disorders such as MS.

\section{Acknowledgment}

The authors are thankful to Philip Ly and Catherin Pallen for their assistance in providing samples and protocols for OL and Oli-neu culture and differentiation.

\section{Study funding}

This study was supported by biomedical operating grant no. 3306 from the MS Society of Canada and through philanthropic support to the Neuroprotection Fund through the VGH \& UBC Hospital Foundation.

\section{Disclosure}

P. Becquart, J. Johnston, C. Vilarino-Guell, and J.A. Quandt report no disclosures. Go to Neurology.org/NN for full disclosures.

\section{Publication history}

Received by Neurology: Neuroimmunology \& Neuroinflammation October 19, 2019. Accepted in final form March 16, 2020. 
Appendix Authors

\begin{tabular}{|c|c|c|}
\hline Name & Location & Contribution \\
\hline $\begin{array}{l}\text { Pierre } \\
\text { Becquart, } \\
\text { MSc }\end{array}$ & $\begin{array}{l}\text { University of British } \\
\text { Columbia, Vancouver, } \\
\text { Canada }\end{array}$ & $\begin{array}{l}\text { Major role in the acquisition of } \\
\text { data and analysis }\end{array}$ \\
\hline $\begin{array}{l}\text { Jake } \\
\text { Johnston, } \\
\text { BSc }\end{array}$ & $\begin{array}{l}\text { University of British } \\
\text { Columbia Vancouver, } \\
\text { Canada }\end{array}$ & $\begin{array}{l}\text { Major role in the acquisition of } \\
\text { data and analysis }\end{array}$ \\
\hline $\begin{array}{l}\text { Carles } \\
\text { Vilariño- } \\
\text { Güell, PhD }\end{array}$ & $\begin{array}{l}\text { University of British } \\
\text { Columbia Vancouver, } \\
\text { Canada }\end{array}$ & RNA-seq analyses \\
\hline $\begin{array}{l}\text { Jacqueline } \\
\text { Quandt, } \\
\text { PhD }\end{array}$ & $\begin{array}{l}\text { University of British } \\
\text { Columbia Vancouver, } \\
\text { Canada }\end{array}$ & $\begin{array}{l}\text { Designed and conceptualized } \\
\text { the study; major role in the } \\
\text { acquisition of data and } \\
\text { analyses; and drafted and } \\
\text { oversaw the manuscript for } \\
\text { intellectual content and } \\
\text { accuracy }\end{array}$ \\
\hline
\end{tabular}

\section{References}

1. Reich DS, Lucchinetti CF, Calabresi PA. Multiple sclerosis. New Engl J Med 2018; 378:169-180.

2. Kobelt G, Thompson A, Berg J, et al. New insights into the burden and costs of multiple sclerosis in Europe. Mult Scler (Houndmills, Basingstoke, England) 2017; 23:1123-1136.

3. Frohman EM, Racke MK, Raine CS. Multiple sclerosis-the plaque and its pathogenesis. New Engl J Med 2006;354:942-955.

4. Lodish H, Berk A, Zipursky SL, Matsudaira P, Baltimore D, Darnell J. Molecular Cell Biology. 4 ed.. New York: W.H. Freeman; 2000.

5. Institute of Medicine. Multiple Sclerosis: Current Status and Strategies for the Future. Washington, DC: The National Academies Press; 2001.

6. Bjartmar C, Trapp BD. Axonal degeneration and progressive neurologic disability in multiple sclerosis. Neurotoxicity Res 2003;5:157-164.

7. Charil A, Filippi M. Inflammatory demyelination and neurodegeneration in early multiple sclerosis. J Neurol Sci 2007;259:7-15.

8. Yong H, Chartier G, Quandt J. Modulating inflammation and neuroprotection in multiple sclerosis. J Neurosci Res 2018;96:927-950.

9. Karussis D, Grigoriadis S, Polyzoidou E, Grigoriadis N, Slavin S, Abramsky O. Neuroprotection in multiple sclerosis. Clin Neurol Neurosurg 2006;108:250-254.

10. Steinman L. Multiple sclerosis: a two-stage disease. Nat Immunol 2001;2:762.

11. Villoslada P. Neuroprotective therapies for multiple sclerosis and other demyelinating diseases. Mult Scler Demyelinating Disord 2016;1:1.

12. Franco PG, Pasquini JM, Silvestroff L. Optimizing culture medium composition to improve oligodendrocyte progenitor cell yields in vitro from subventricular zonederived neural progenitor cell neurospheres. PLoS One 2015;10:e0121774.

13. Chaerkady R, Letzen B, Renuse S, et al. Quantitative temporal proteomic analysis of human embryonic stem cell differentiation into oligodendrocyte progenitor cells. Proteomics 2011;11:4007-4020.

14. Pfeiffer SE, Warrington AE, Bansal R. The oligodendrocyte and its many cellular processes. Trends Cell Biol 1993;3:191-197.

15. El Waly B, Macchi M, Cayre M, Durbec P. Oligodendrogenesis in the normal and pathological central nervous system. Front Neurosci 2014;8:145.

16. Cai J, Zhu Q Zheng K, et al. Co-localization of Nkx6.2 and Nkx2.2 homeodomain proteins in differentiated myelinating oligodendrocytes. Glia 2010;58: $458-468$.

17. Billon N, Tokumoto Y, Forrest D, Raff M. Role of thyroid hormone receptors in timing oligodendrocyte differentiation. Dev Biol 2001;235:110-120.

18. Canoll PD, Musacchio JM, Hardy R, Reynolds R, Marchionni MA, Salzer JL. GGF/ Neuregulin is a neuronal signal that promotes the proliferation and survival and inhibits the differentiation of oligodendrocyte progenitors. Neuron 1996;17: 229-243.

19. McKinnon RD, Piras G, Ida JA Jr, Dubois-Dalcq M. A role for TGF-beta in oligodendrocyte differentiation. J Cell Biol 1993;121:1397-1407.

20. Barres BA, Burne JF, Holtmann B, Thoenen H, Sendtner M, Raff MC. Ciliary neurotrophic factor enhances the rate of oligodendrocyte generation. Mol Cell Neurosci 1996;8:146-156.

21. Raible DW, McMorris FA. Oligodendrocyte differentiation and progenitor cell proliferation are independently regulated by cyclic AMP. J Neurosci Res 1993;34: 287-294.

22. Omar M, Bock P, Kreutzer R, et al. Defining the morphological phenotype: $2^{\prime}, 3^{\prime}$ cyclic nucleotide $3^{\prime}$-phosphodiesterase (CNPase) is a novel marker for in situ detection of canine but not rat olfactory ensheathing cells. Cell Tissue Res 2011;344: 391.
23. Kewley RJ, Whitelaw ML, Chapman-Smith A. The mammalian basic helix-loop-helix/ PAS family of transcriptional regulators. Int J Biochem Cell Biol 2004;36:189-204.

24. Drutel G, Heron A, Kathmann M, et al. ARNT2, a transcription factor for brain neuron survival?. Eur J Neurosci 1999;11:1545-1553.

25. Laiosa MD, Lai ZW, Thurmond TS, et al. 2,3,7,8-tetrachlorodibenzo-p-dioxin causes alterations in lymphocyte development and thymic atrophy in hemopoietic chimeras generated from mice deficient in ARNT2. Toxicol Sci 2002;69. $117-124$

26. Hosoya T, Oda Y, Takahashi S, et al. Defective development of secretory neurones in the hypothalamus of Arnt2-knockout mice. Genes Cells 2001;6:361-374.

27. Keith B, Adelman DM, Simon MC. Targeted mutation of the murine arylhydrocarbon receptor nuclear translocator 2 (Arnt2) gene reveals partial redundancy with Arnt. Proc Natl Acad Sci U S A 2001;98:6692-6697.

28. Wines ME, Tiffany AM, Holdener BC. Physical localization of the mouse aryl hy drocarbon receptor nuclear translocator-2 (Arnt2) gene within the $\mathrm{c} 112 \mathrm{~K}$ deletion. Genomics 1998;51:223-232.

29. Rahim T. Investigating the Regulation of ARNT2, a Neuroprotective Protein, in Models of Multiple Sclerosis. Masters Thesis University of British Columbia; Vancouver, Canada, 2016.

30. Rahim T, Becquart P, Baeva ME, Quandt J. Expression of the neuroprotective protein aryl hydrocarbon receptor nuclear translocator 2 correlates with neuronal stress and disability in models of multiple sclerosis. J Neuroinflammation 2018;15: 270.

31. Neil S, Huh J, Baronas V, et al. Oral administration of the nitroxide radical TEMPOL exhibits immunomodulatory and therapeutic properties in multiple sclerosis models. Brain Behav Immun 2017;62:332-343.

32. Aiga M, Levinson JN, Bamji SX. N-cadherin and neuroligins cooperate to regulate synapse formation in hippocampal cultures. J Biol Chem 2011;286:851-858.

33. Wang PS, Wang J, Xiao ZC, Pallen CJ. Protein-tyrosine phosphatase alpha acts as an upstream regulator of Fyn signaling to promote oligodendrocyte differentiation and myelination. J Biol Chem 2009;284:33692-33702.

34. Jung M, Krämer E, Grzenkowski M, et al. Lines of murine oligodendroglial precursor cells immortalized by an activated neu tyrosine kinase show distinct degrees of interaction with axons in vitro and in vivo. Eur J Neurosci 1995; 7 $1245-1265$

35. Fratangeli A, Parmigiani E, Fumagalli M, et al. The regulated expression, intracellular trafficking, and membrane recycling of the P2Y-like receptor GPR17 in Oli-neu oligodendroglial cells. J Biol Chem 2013;288:5241-5256.

36. Dobin A, Davis CA, Schlesinger F, et al. STAR: ultrafast universal RNA-seq aligner. Bioinformatics 2013;29:15-21.

37. Trapnell C, Williams BA, Pertea G, et al. Transcript assembly and quantification by RNA-Seq reveals unannotated transcripts and isoform switching during cell differentiation. Nat Biotechnol 2010;28:511-515.

38. Huang da W, Sherman BT, Lempicki RA. Systematic and integrative analysis of large gene lists using DAVID bioinformatics resources. Nat Protoc 2009;4:44-57.

39. Söhl G, Hombach S, Degen J, Odermatt B. The oligodendroglial precursor cell line Oli-neu represents a cell culture system to examine functional expression of the mouse gap junction gene connexin29 (Cx29). Front Pharmacol 2013;4:83.

40. Long PM, Tighe SW, Driscoll HE, et al. Acetate supplementation induces growth arrest of NG2/PDGFR $\alpha$-positive oligodendroglioma-derived tumor-initiating cells PLoS One 2013;8:e80714.

41. Dugas JC, Tai YC, Speed TP, Ngai J, Barres BA. Functional genomic analysis of oligodendrocyte differentiation. J Neurosci 2006;26:10967-10983.

42. Nave K-A, Trapp BD. Axon-glial signaling and the glial support of axon function. Annu Rev Neurosci 2008;31:535-561.

43. DeLuca GC, Williams K, Evangelou N, Ebers GC, Esiri MM. The contribution of demyelination to axonal loss in multiple sclerosis. Brain 2006;129:1507-1516.

44. Hao N, Bhakti VL, Peet DJ, Whitelaw ML. Reciprocal regulation of the basic helixloop-helix/Per-Arnt-Sim partner proteins, Arnt and Arnt2, during neuronal differentiation. Nucleic Acids Res 2013;41:5626-5638

45. Zhang Y, Chen K, Sloan SA, et al. An RNA-sequencing transcriptome and splicing database of glia, neurons, and vascular cells of the cerebral cortex. J Neurosci 2014;34: 11929-11947.

46. Robinson AP, Harp CT, Noronha A, Miller SD. The experimental autoimmune encephalomyelitis (EAE) model of MS: utility for understanding disease pathophysiology and treatment. Handbook Clin Neurol 2014;122:173-189.

47. Woods CG. Human microcephaly. Curr Opin Neurobiol 2004;14:112-117.

48. Webb EA, AlMutair A, Kelberman D, et al. ARNT2 mutation causes hypopituitarism, post-natal microcephaly, visual and renal anomalies. Brain 2013;136: 3096-3105

49. Dougherty EJ, Pollenz RS. Analysis of Ah receptor-ARNT and Ah receptor-ARNT2 complexes in vitro and in cell culture. Toxicol Sci 2008;103:191-206.

50. Ooe N, Saito K, Kaneko H. Characterization of functional heterodimer partners in brain for a bHLH-PAS factor NXF. Biochim Biophys Acta 2009;1789:192-197.

51. Ernfors P, Lee KF, Jaenisch R. Mice lacking brain-derived neurotrophic factor develop with sensory deficits. Nature 1994;368:147-150.

52. Jones KR, Farinas I, Backus C, Reichardt LF. Targeted disruption of the BDNF gene perturbs brain and sensory neuron development but not motor neuron development. Cell 1994;76:989-999.

53. Binder DK, Scharfman HE. Brain-derived neurotrophic factor. Growth Factors 2004 22:123-131.

54. Hall J, Thomas KL, Everitt BJ. Rapid and selective induction of BDNF expression in the hippocampus during contextual learning. Nat Neurosci 2000;3:533-535. 
55. Patterson SL, Abel T, Deuel TA, Martin KC, Rose JC, Kandel ER. Recombinant BDNF rescues deficits in basal synaptic transmission and hippocampal LTP in BDNF knockout mice. Neuron 1996;16:1137-1145.

56. Sharma N, Pollina EA, Nagy MA, et al. ARNT2 tunes activity-dependent gene expression through NCoR2-mediated repression and NPAS4-mediated activation. Neuron 2019;102:390-406 e399.

57. Colakoglu G, Bergstrom-Tyrberg U, Berglund EO, Ranscht B. Contactin-1 regulates myelination and nodal/paranodal domain organization in the central nervous system. Proc Natl Acad Sci U S A 2014;111:E394-E403.
58. Sekine H, Mimura J, Yamamoto M, Fujii-Kuriyama Y. Unique and overlapping transcriptional roles of arylhydrocarbon receptor nuclear translocator (Arnt) and Arnt 2 in xenobiotic and hypoxic responses. J Biol Chem 2006;281: 37507-37516.

59. Yuen TJ, Silbereis JC, Griveau A, et al. Oligodendrocyte-encoded HIF function couples postnatal myelination and white matter angiogenesis. Cell 2014;158:383-396.

60. Zhang Y, Chen K, Sloan SA, et al. An RNA-sequencing transcriptome and splicing database of glia, neurons, and vascular cells of the cerebral cortex. J Neurosci 2014;34: 11929. 


\section{Neurology \\ Neuroimmunology \& Neuroinflammation}

Oligodendrocyte ARNT2 expression is altered in models of MS

Pierre Becquart, Jake Johnston, Carles Vilariño-Güell, et al.

Neurol Neuroimmunol Neuroinflamm 2020;7;

DOI 10.1212/NXI.0000000000000745

This information is current as of May 21, 2020

\section{Updated Information \& Services}

References

Subspecialty Collections

Permissions \& Licensing

Reprints including high resolution figures, can be found at:

http://nn.neurology.org/content/7/4/e745.full.html

This article cites 57 articles, 10 of which you can access for free at: http://nn.neurology.org/content/7/4/e745.full.html\#\#ref-list-1

This article, along with others on similar topics, appears in the following collection(s):

All Immunology

http://nn.neurology.org//cgi/collection/all_immunology

Autoimmune diseases

http://nn.neurology.org//cgi/collection/autoimmune_diseases

Multiple sclerosis

http://nn.neurology.org//cgi/collection/multiple_sclerosis

Information about reproducing this article in parts (figures,tables) or in its entirety can be found online at:

http://nn.neurology.org/misc/about.xhtml\#permissions

Information about ordering reprints can be found online:

http://nn.neurology.org/misc/addir.xhtml\#reprintsus

Neurol Neuroimmunol Neuroinflamm is an official journal of the American Academy of Neurology.

Published since April 2014, it is an open-access, online-only, continuous publication journal. Copyright

Copyright $\odot 2020$ The Author(s). Published by Wolters Kluwer Health, Inc. on behalf of the American

Academy of Neurology.. All rights reserved. Online ISSN: 2332-7812.

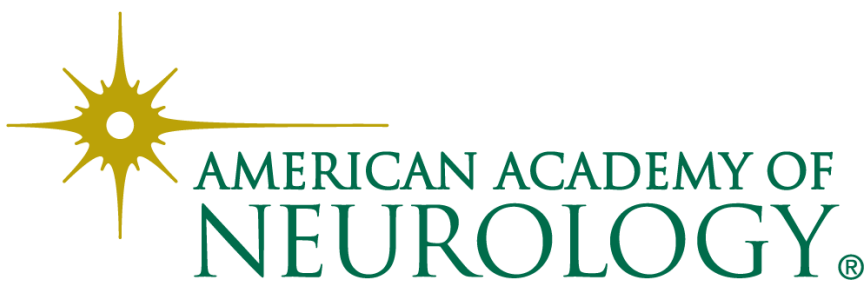

